"Your old patient died at last (July 28) very suddenly. He was seized with a fit of dyspnoca, followed by the expectoration of several mouthfuls of blood. The difficulty of breathing rapidly increased; and he died, I think, about four hours after the commencement of the attack."

Dr. Bell also informs me, that a large tumour appeared some weels before his death in the abdomen; it pressed on the rectum, and caused much pain, diarrhoa, etc. I very much regret to add that no post mortem examination could be obtained.

Remakks. I have preferred to give an incomplete account of this case, to allowing all record of symptoms which appear so uncommon to be lost. An elderly man lives from April 15.j2 to July 185i3, with a pulse averaging about 32; and at last dies, more alparrently from the effect of some of the evident symptoms, than from the obscure cause of the disease. The physician, Dr. Bell, under whose care Mr. S. placed himself in May $1 \times 52$, believes that he had suffered for some years from hypertrophy of the heart; that the run in April ruptured the chordce tendinece of the mitral valve; and that the alteration in the number of pulsations depended either on some effusion about the origin of the eighth pair of nerves, or on obscure brain disease. My own opinion coincided with Dr. Bell's, except that I thought there was some pericardial effusion, though not to any great extent. The treatment was very simple. The points chiefly attended to were, the avoidance of all excitement, simple diet, and a warm dry air, with ample clothing.

Altriuchum, Cheshirc, Septemler 10, 1 s53.

\section{FATAL POISONING FROM ARSENIC TAKEN TO INDUCE ABORTION.}

\section{By 'THOMIS BROWN, Esq.}

Os Moniliy, October 21st, 1850, I was requested to see Sarah Weston, at the Lock, Weston-on-Trent, a singlc woman, aged 24 ycars. On my arrival, I ascertained that she came from her situation as domestic servant at Alvaston, a distance of seven miles, on the Saturday evening previous; and that during the journey she suffered from pain and vomiting, the latter continuing on her arrival at home, where she was premittirely lelivered (by a midwife) of a male child. It was not until Monday morning that the friends with whom she lived thought it necessary to send for a surgeon; and, in the neantime, all traces of the matter ejectel from tlie stomach had been removed. I found my patient delirious aind unconscious, with a cadaverous countenamee, and ficelile rapid pulse. The abdomen was tender on fressure, and somewliat distended: there was urgent thirst and cunstint jactitation. Leeches to the abdomen and an opiate were at once ordered; but no alleviation of the sympitoms took place; and death occurred within seven hours from the time I first saw her. In two hours afterwards, the infant of which she had been delivered also died.

Being called in after every actual symptom of poisoning was absent, I attributed the death to peritonitis: and the bodies were speedily interred, without, however, any medical certificate from myself or any other medical practitioner. On the second day of interment, some rumour prevailed that the sulject of our case had been the victim of foul play; and this report gaining ground, the coroner for the county at once ordered the body to be exhumed. This was done on the 2ith of October, 1850 , just three days subsequent to interment.

In company with a neighbouring surgeon (Mr. John Smith), I procecded to the barn where the body was exposed for examination. On carefully inspecting the osophagus and cardiac portion of the stomach, there was no appearance of poisoning; lut as we traced downwards near the pyloric orifice, we at once perceived erosion or ulceration of the mucous unembrane, with a well defined line of demarcation.
I conveyed the stomach to my surgery, and the contents were tested by Marsh's apparatus, as well as by some of the more simple or uncertain modes; but having regand for the stomach (as a specimen of the action of arsenic, which was forwarded to the museum of the Sheffield Infirmary), I forbore subjecting the same to strict analysation, particularly so, as in the evidence adduced at the inquest it was clearly proved that the deceased had procured arsenic, and had taken it for the purpose of procuring abortion. The verdict was in accordance with this evidence.

September 22, 1853.

\section{PERISCOPIC REVIEW.}

\section{PRACTTCE OF MEDICINE AND PATHOLOGY.}

\section{DEGENERATION OF MUSCLES: MICROSCOPIC EXAMINATION.}

The Union Médicale for May 7th, contains an account given by J)r. Duciresise, of an examination made by him of the right arm of a man who had died with muscular atropby.

'The suljject was a man, agred $3 \dot{2}$, a mountebank, who had been under the care of $\mathbf{M}$. Cruveilhier, labouring under general atroplyy of the muscles, with loss of power of motion. Diglutition, speech, and respiration, gradually became impeded: and he died during an attack of influenza, from inability to dislodge the mucus which accumulated in the bronchial tubes.

A very full account of the case, and of the post mortcm examination, is contained in an essay read before the Academy of Medicine by M. Cruveillier, and published in the Gazette Médicale for A pril $16 \mathrm{th}_{\mathrm{h}}, 185 \mathrm{~s}$.

All the muscles, although much atrophied, had almost preserved their normal colour; these muscles had undergone no change of structure. The brachialis anticus alone presented a pale grey colour. Several of the muscles on the front of the pale grey colour. Several of the musces some muscular fibres fore-arm were only tenilons, ware for the most part of good colour, and of normal structure. There were no traces whatcolour, and of normal structure. ever of the pronator muscular fibres belonging to the superficial and deep Hexors, and to the pronator quadratus. 'These fibres vuried in colour from yellowish to pale grey. The fibres having the latter colour had the appearance of gelatine more than of muscle. All the muscles of the palmar surface of the hand were in the last stage of depraved nutrition, except some muscular filres of the hypothenar eminence.

The muscular fibres were examined under the mirroscope by Dr. Ducheune and NM. Aran and Mandl. Their volume and texture were normal in those muscles which had preserved their colour, and which had been ascertained during life to be obedient to the electric or the voluntary stimulus.

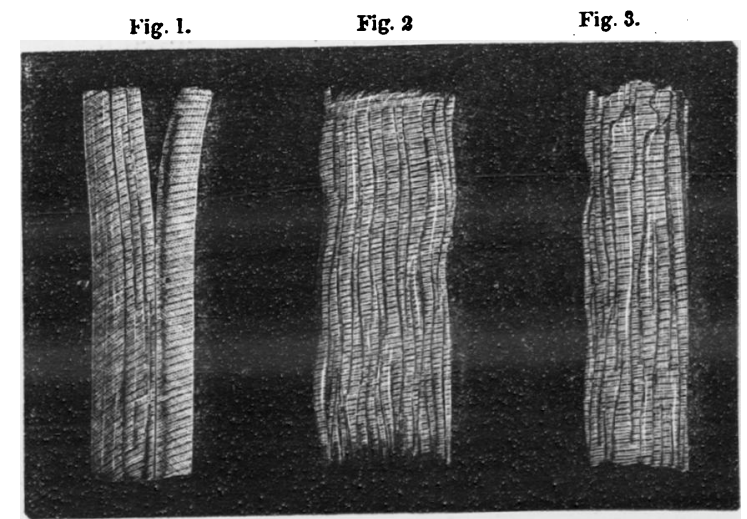

Fig. 1 represents healthy fibro with transverse striz. Somo longitudinal

fibres are seen. strix are less distinct; they sre frequently interrupted, are loot here and there, and at last are altogether displaced. Tho longitw dinal fibres become more distinct. 